\title{
MARGINALLY ATTACHED TO THE LABOUR FORCE
}

\author{
Ayesha Udugampolage \\ Kunal D'Souza
}

Statistics NZ, Wellington

\begin{abstract}
Since the beginning of the decade, the numbers of unemployed - who are usually regarded as a reserve labour force have reached historically low levels, with a strong concomitant demand for labour. This has resulted in an increasing interest in issues pertaining to labour force participation.

Using data from Statistics New Zealand's Household Labour Force Survey, this article explores the characteristics of those who are not in the labour force, but still have a marginal attachment to it. In times of low unemployment, this group may serve as an alternative source of potential labour supply, while in the longer run it may be drawn upon to increase the working-age population's participation in the labour force.
\end{abstract}

\section{Introduction}

This paper reports on an analysis of the component of New Zealand's working-age population referred to as 'marginally attached to the labour force'. This group of people is officially defined as not in the labour force and so is not reflected in official employment and unemployment statistics.

Using data from Statistics New Zealand's Household Labour Force Survey, this article explores the characteristics of those who are not in the labour force, but still have a degree of attachment to it. That is, they are not currently actively looking for work, or are not currently available to start a job for various reasons.

With the low levels of unemployment observed recently, alongside other social phenomena such as an ageing workforce and falling numbers of immigrants, there is increasing interest in issues around labour force participation. In particular there is interest in increasing labour force participation to increase productivity, particularly among young women aged 25 - 34 (Bryant et al, 2004). The Organisation for Economic Cooperation and Development (OECD) has suggested that increases in labour force participation could make a substantial contribution towards reducing the gap in per capita incomes between New Zealand and the rest of the OECD countries.

Since the beginning of the decade, the numbers of unemployed - who are usually regarded as a reserve labour force - have reached historically low levels, with a strong concomitant demand for labour. In such times, the marginally attached group may serve as an alternative source of potential labour supply, and in the longer run it may be drawn upon to increase the working-age population's participation in the labour force.

It follows that the best time to analyse marginally attached groups to understand their behaviour and the underlying reasons for not being in the labour force occurs when the reserve labour pool is contracted and the unemployment rate is at record low levels.

\section{What does Marginal Attachment to the Labour Force Mean?}

The definitions of employment and unemployment used by Statistics New Zealand conform closely with International Labour Organization (ILO) definitions to ensure international comparability and internal consistency. The total labour force is made up of all those who are defined as employed or unemployed. However, persons excluded from the labour force by the official ILO definitions may still exhibit a degree of attachment to the labour force. The relative strength of the attachment will vary, depending on a range of factors.

Traditional labour market theory regards the unemployed as a reserve for the employed in the labour force, because this group of jobless is available to start work, and is also considered to be actively seeking work. A higher degree of attachment to the labour force translates to relatively lower barriers to entering employment, or a higher propensity to enter employment. Therefore, understanding the characteristics of those who are not in the labour force but marginally attached to it may help, especially in times of low unemployment, in the forming of policies to overcome barriers to employment and to encourage movement into the labour force, resulting in increased economic activity.

The diagram below shows how the working-age population can be categorised into different groups. Putting aside the employed, the remainder of the working age population can be divided into four groups using two criteria - available to work and actively seeking work. Two of these groups are considered to be marginally attached to the labour force: those who are actively seeking but have not been available to start work in the week prior to the reference week; and those who despite being available for work, are not considered to be actively 
seeking work (including people whose job search method has only involved seeking through newspapers). Note that this latter group includes 'discouraged workers' - those not seeking work because they believe they lack skills, are the wrong age, or believe there is not suitable work available in their area.

\section{Figure 1: Conceptual Representation of the Working} Age Population

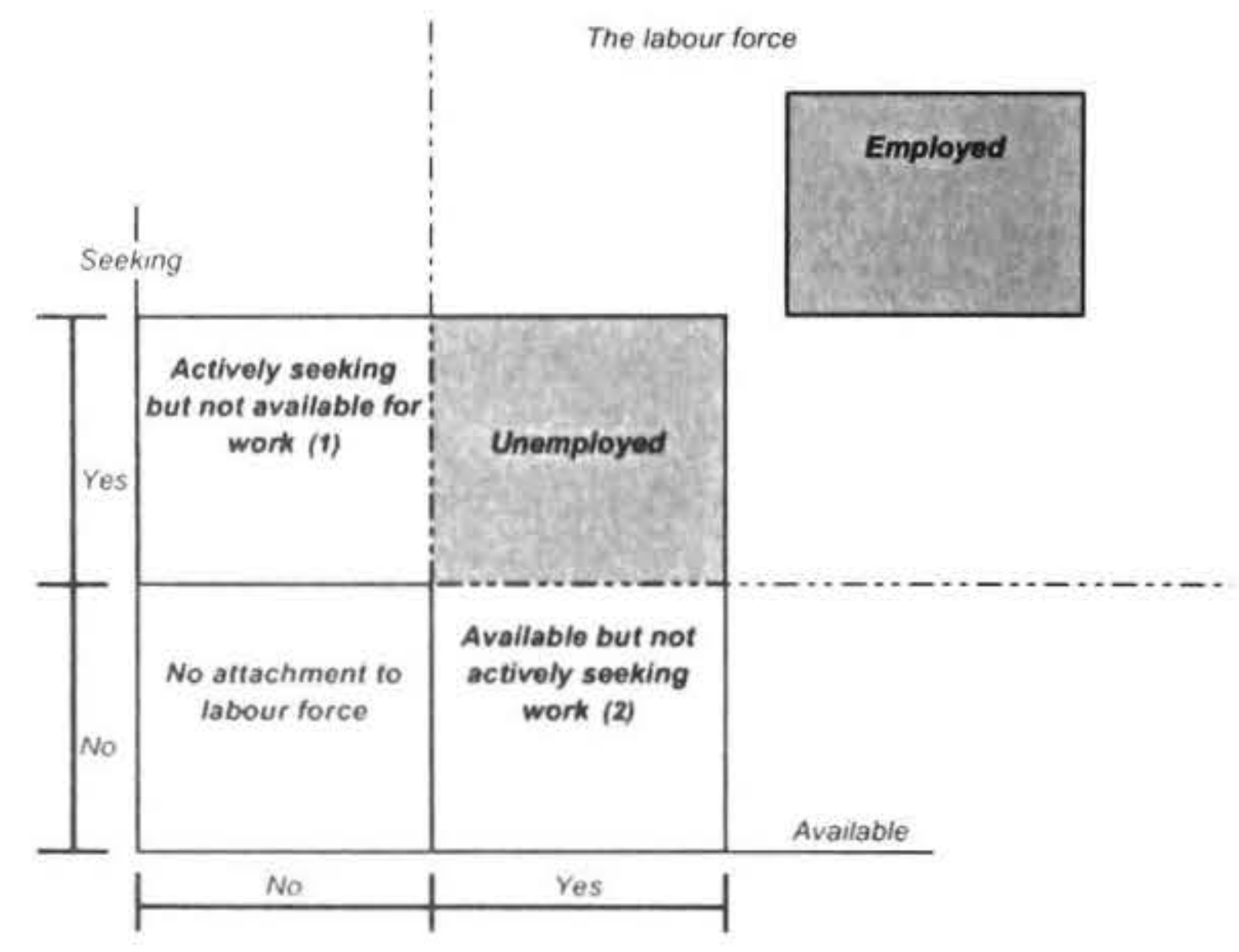

(1) People actively seeking but not avalable to start work in the week prior to the reference week (2) This indudes peobie whose pob-search method has only involved seeking through newspapers

\section{The Marginally Attached Population in New Zealand}

For the year ended March 2004, there were approximately 72.000 people who were not in the New Zealand labour force, but had some degree of attachment to it. Of these, 20,000 were actively seeking work but not available to start, and the remaining 53,000 people were available but not considered to be actively seeking work.

The number of those available but not actively seeking work, including discouraged workers, has fallen along with official unemployment (Figure 2). The number of unemployed in the survey series has nearly halved since the carly 1990s, while the number of those available but not actively secking employment fell from 76,000 for the year ended March 1992 (when unemployment was 180.000 ) to its current level of 53,000 (with unemployment at 92,000) for the year ended March 2004. The number of those who were actively seeking but not available, by contrast, appears not to be correlated with unemployment.

These movements are consistent with trends in time series data from both the United Kingdom and Australia.

\section{Actively Seeking but not Available for Work}

For the year ended March 2004, those actively seeking work but not available comprised 17.5 percent of all people who were actively seeking employment. This proportion has gradually increased in recent years. For the year ended March 1992 (when unemployment was high), those unavailable to start work represented only 7.3 percent of all people actively seeking employment. This indicates that availability to work is not influenced by the ease with which employment can be found. Looking at the reasons for being unavailable to work (Figure 3) helps to understand the barriers to this group entering the labour market.

Figure 2: Persons Unemployed and Persons Marginally Attached to the Labour Force

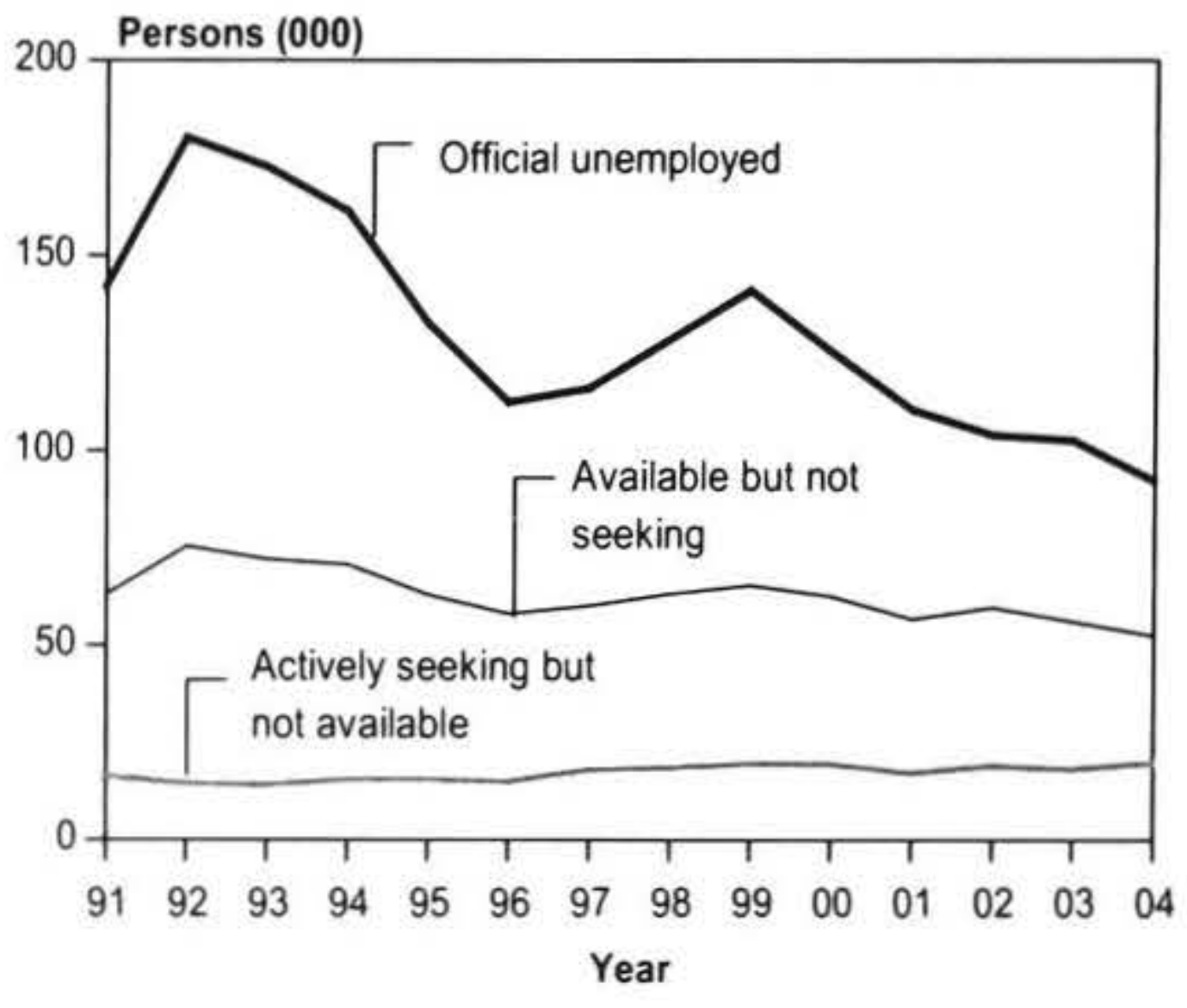

Figure 3: Persons Actively Seeking Work but Not Available

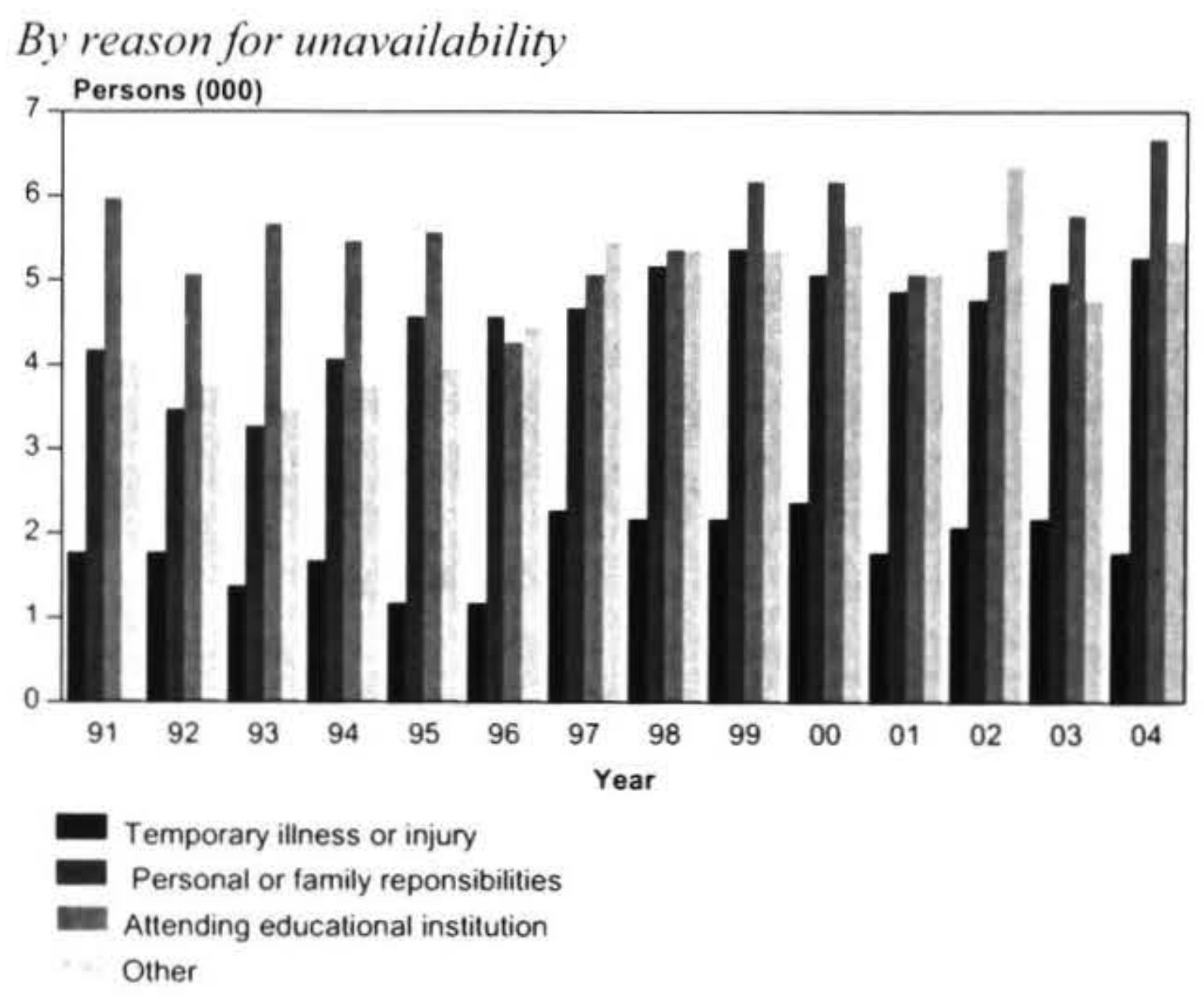

For the year ended March 2004, the main reasons for being unavailable to work were: attending an educational institution (34.3 percent); personal or family responsibilities (27.1 percent); and temporary illness or injury ( 9.3 percent), with 28.2 percent providing other, unclassified reasons.

A comparison of the category 'actively seeking but not available' with all job seekers shows that a higher proportion of this group are part-time job seekers. For the year ended March 2004, of all people who were seeking to work (including those looking through newspapers only), 50.2 percent sought full-time work, compared with 30.4 percent of those actively seeking work but not available. This is a tendency also noted in previous years (Table 1). 
Table 1: Proportions Seeking Full-time Employment

\begin{tabular}{|l|c|c|}
\hline \multirow{2}{*}{1991} & $\begin{array}{c}\text { Actively seeking work } \\
\text { but not available }\end{array}$ & $\begin{array}{c}\text { All people } \\
\text { seeking jobs }\end{array}$ \\
\cline { 2 - 3 } 19 & \multicolumn{2}{|c|}{ Percent } \\
\cline { 2 - 3 } 1992 & 44.1 & 69.0 \\
1993 & 44.0 & 73.3 \\
1994 & 44.6 & 72.6 \\
1995 & 42.5 & 72.7 \\
1996 & 40.7 & 68.9 \\
1997 & 34.2 & 63.1 \\
1998 & 39.7 & 60.1 \\
1999 & 35.5 & 60.6 \\
2000 & 39.1 & 61.1 \\
2001 & 37.3 & 59.5 \\
2002 & 33.4 & 57.9 \\
2003 & 30.8 & 52.7 \\
2004 & 35.9 & 52.8 \\
\hline
\end{tabular}

However, the gap between the proportion of those seeking full-time and part-time employment has decreased in the group that is actively seeking but not available (Figure 4). In the year ended March 1991, 44.1 percent of those seeking work but not available to start sought full-time employment, compared with 24.8 percent seeking part-time employment. In the year ended March 2004, 30.4 percent in this group said that they were seeking full-time employment, compared with 31.8 percent who said that they were seeking part-time work. The not applicable group did not specify a full-time or part-time employment preference.

\section{Figure 4: People Actively Seeking Work but Not} Available

Proportion of full-time versus part-time work sought

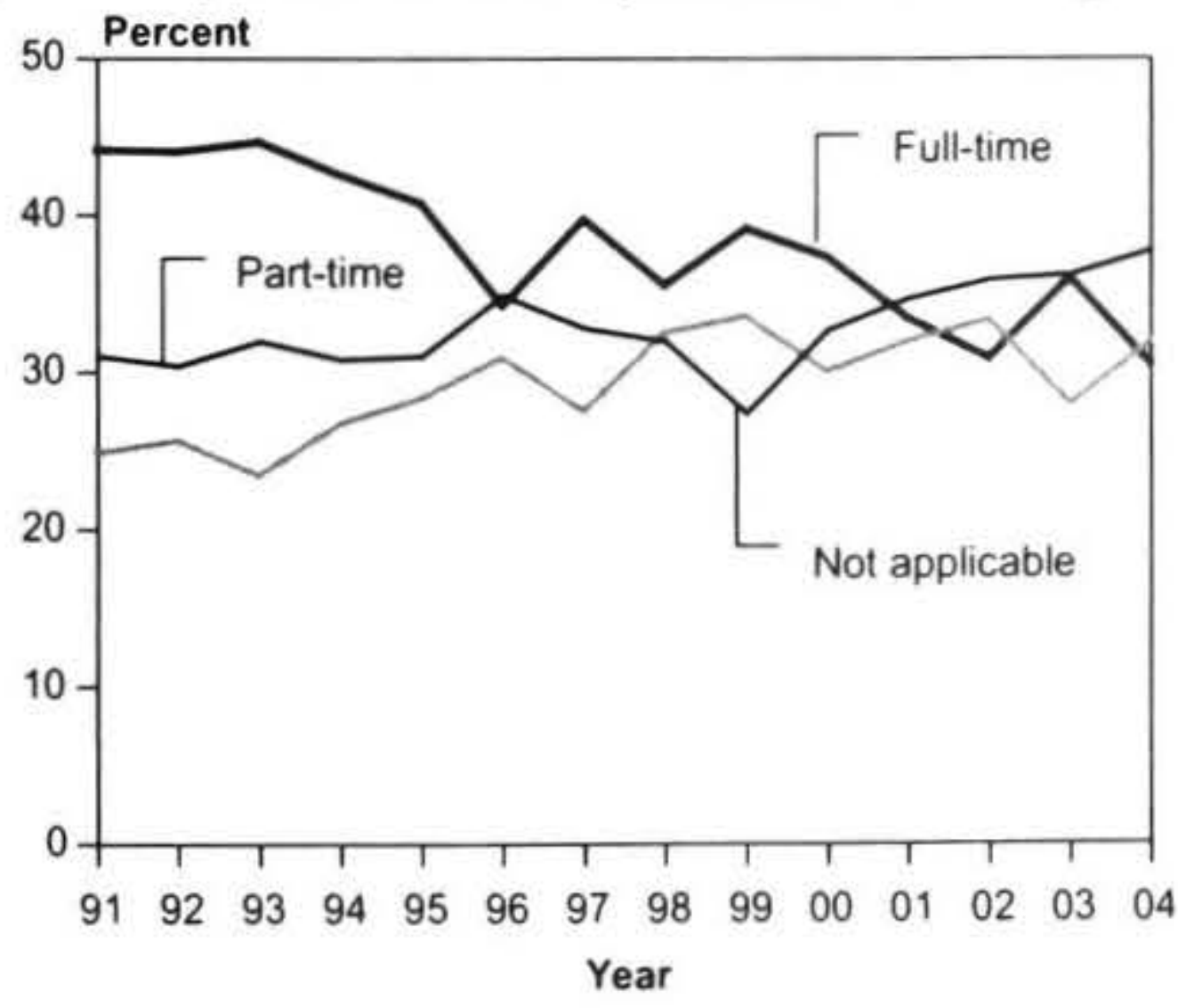

\section{Available but not Actively Seeking Work}

For the year ended March 2004, 53,000 people were not included in the labour force because they were available but not considered to be actively seeking work. This is the lowest since the year ended March 1989 and is a fall of 3,000 from March 2003. Discouraged workers are included in this group. In general, when the labour market is performing well (ie when the unemployment rate is low), the number of discouraged workers declines. Similar movements are evident in overseas findings.

Reasons for not actively seeking work while available were: attending an educational institution (23.6 percent), looking through newspapers only (19.4 percent), discouraged (12.1 percent), illness or injury of self or others ( 8.8 percent $)$, unable to find suitable childcare $(8.2$ percent) and other reasons ( 28.0 percent) for those who specified a reason.

The main activity for most people in this group was studying ( 28.9 percent), followed by staying home to look after children ( 21.7 percent), and staying at home but not looking after children ( 20.3 percent). Those who were doing something else (17.7 percent) or retired (11.4 percent) comprised the smallest portions of this group for those who specified a main activity.

\section{The Impact of Labour Market Conditions on those who are Available but not Seeking Work}

The relationship various subgroups in the marginally attached category have with the labour force may assist in understanding the extent to which adverse labour market conditions are a barrier to entry to the labour market. The unemployment rate can be used as an indicator of prevailing labour market conditions. The following section discusses the relationship between marginally attached subgroups and the unemployment rate.

If the unemployment rate is considered an indicator of labour market conditions, an improved labour market means a low unemployment rate and vice versa. The unemployment rate was 10.6 percent in March 1992 and 4.5 percent in March 2004, reflecting improved labour market conditions.

The number of marginally attached people at home without childcare responsibilities has fallen as labour market conditions have improved. Additionally, the number of people whose main activity is looking after children has generally fallen as labour market conditions have improved, suggesting a latent attachment to the labour market. This is consistent with time series data for the United Kingdom which shows the number of workers and persons who look after family and/or home has declined as the number of unemployed has dropped.

The number of retired people, on the other hand, does not vary as much with labour market conditions, despite this component of the working-age population traditionally being considered a reserve for the labour force. This has 
implications for the supply of labour in times of low unemployment.

The number of people available but not actively seeking work who were studying has increased as labour market conditions have improved. A similar trend has been seen in the United Kingdom. This could be due to a range of factors, such as more people being encouraged to engage in education, changes in policies, and changes in social expectations.

Figure 5 shows the relationship between labour market conditions and people's intentions to seek work. When the unemployment rate is high, many people respond that they do not know whether or not they intend to seek work.

Figure 5: Work-seeking Intentions Within the Next Two Years

Proportion of persons available but not seeking work

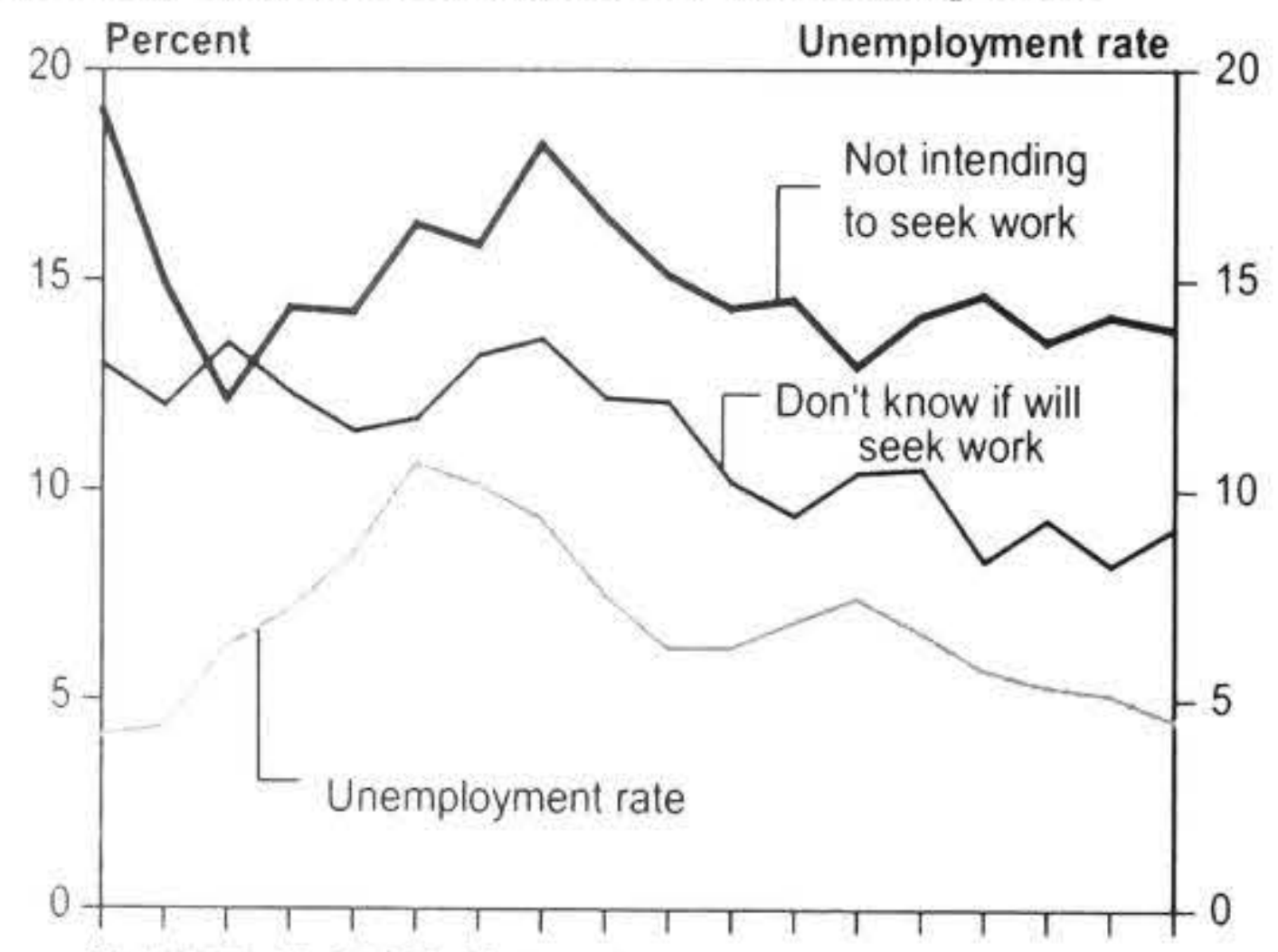

878889909192939495969798990001020304 Year

For the year ended March 2004, of those available but not actively sceking work, 7,200 people said they did not intend to seek work within the next two years and 4,800 said they did not know whether they would seek work in the next two years. This contrasts with the levels seen at times of more adverse labour market conditions, such as the year ended March 1994, when 12,900 people said they would not be secking work within the next two years and 9,600 people did not know whether they would seek work in the next two years.

Figure 6 shows that the number of discouraged workers is closely related to unemployment in the labour market. For the year ended March 2004, 11.9 percent of those available but not actively seeking work were discouraged workers. This compares with the high of 24.9 percent for the year ended March 1994, when unemployment was 9.3 percent of the labour force.

Figure 7 shows the relationship between the time last worked and the labour market conditions for the group that is available but not seeking work. In the year ended March 2004, about a third of people not actively seeking while being available for work had worked less than a year earlier. In comparison, 13.7 percent had worked more than a year earlier but less than two years earlier and 15.6 pereent of those available but not actively secking work had last worked between two and five years earlier, while 16.7 percent had last worked more than five years earlier. Nearly one-fifth (18.7 percent) of this group had never worked before.

\section{Figure 6: Unemployment Rate and Proportion of Persons Available but Not Seeking Work who are Discouraged Workers}

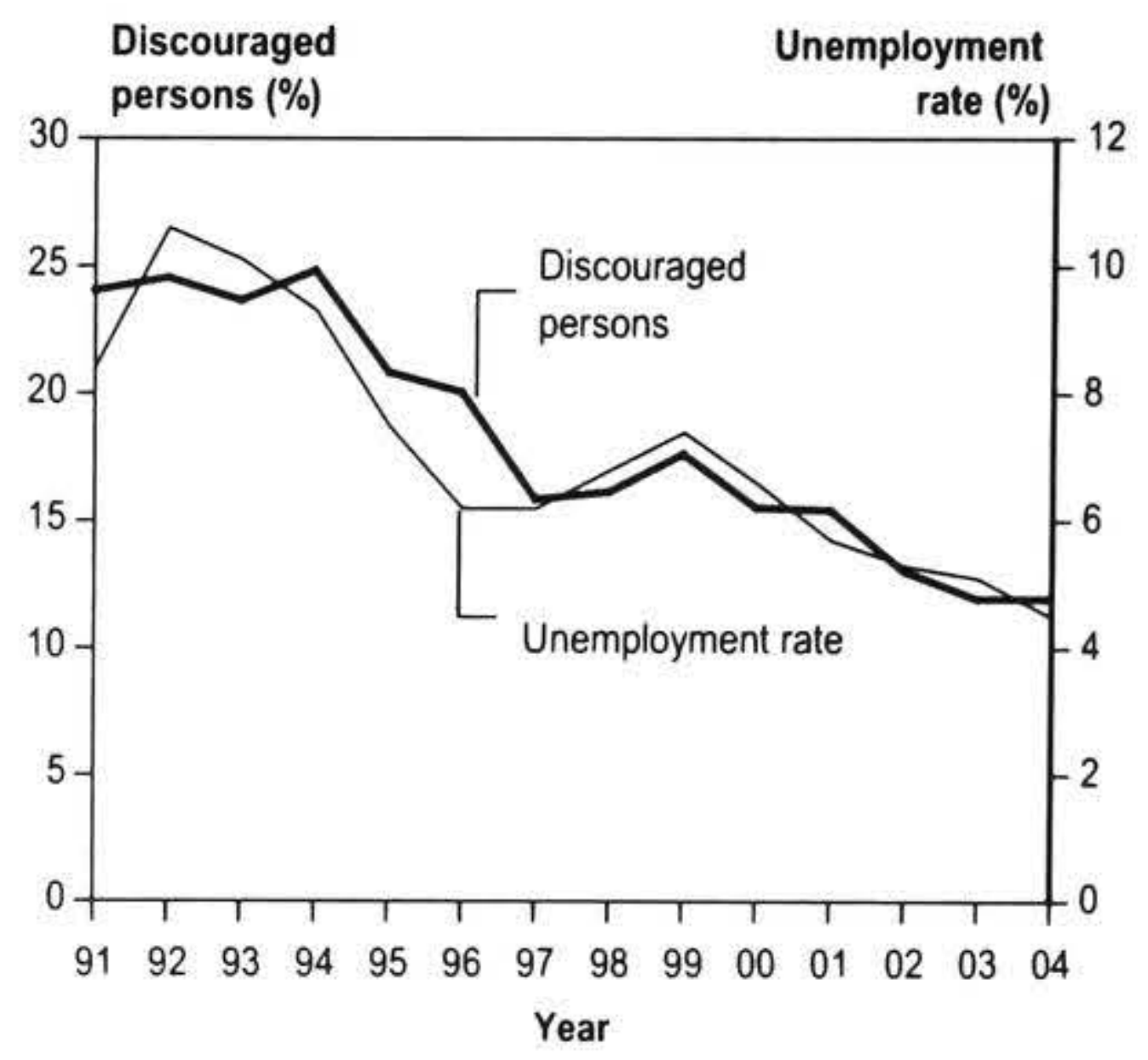

A relationship between the unemployment rate and those who were employed less than one year earlier is not apparent; neither is such a relationship for those who last worked more than five years earlier. However, proportions of those who last worked between two and five years earlier appear to rise with high unemployment and drop with low unemployment, suggesting that this group is most affected by labour market conditions.

\section{Figure 7: Unemployment Rate and Proportion of Persons Available but Not Actively Seeking Work}

Time since last worked

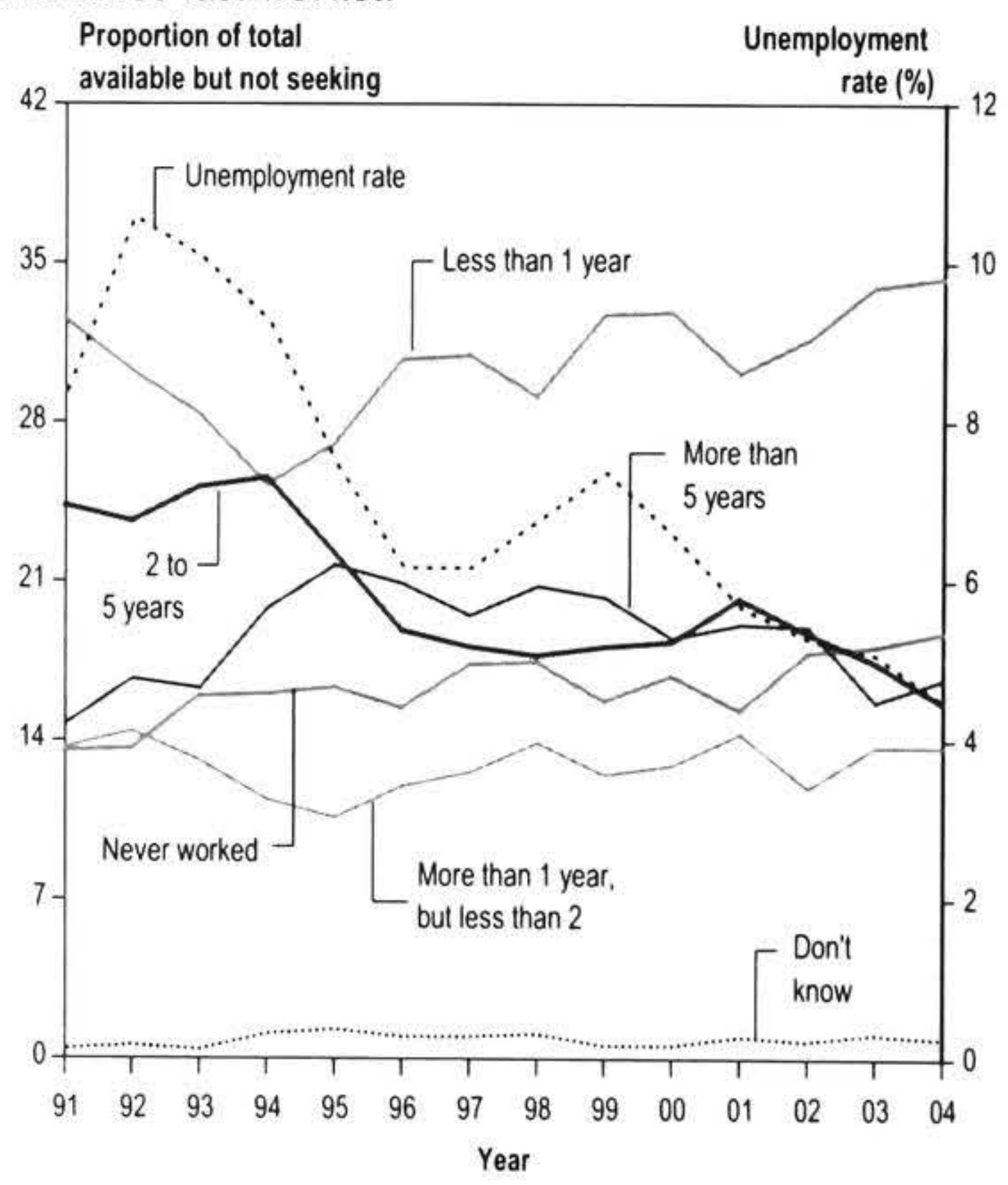




\section{Distribution of Educational Attainment across those who are Available but not Seeking Work}

There is a greater likelihood that the marginally attached who are available but not seeking work will have no educational qualification when compared to the rest of the working-age population. For the year ended March 2004, 38.2 percent of those available but not seeking work had no qualifications, compared to 24.6 percent of the total working age population and 17.4 percent of the employed. This relationship is also apparent for those with basic qualifications. Of those available but not seeking work, 29.3 percent have only a school qualification, compared with 27.1 percent of the workingage population and 25.5 percent of those employed. However, those with both post-school and school qualifications are under-represented among those available but not seeking work, making up 21.9 percent of this group, compared with 38.9 percent of the workingage population and 47.4 percent of those employed.

In recent years, the proportion of people available but not actively seeking work, and with no qualifications, has steadily fallen, from more than half of this group in the early 1990 s, to 38.2 percent for the year ended March 2004. A similar tendency is seen in the total working-age population and among those employed, reflecting the increased emphasis on gaining qualifications in the working-age population generally. Contemporaneous increases in the number of people with post-school but no school qualifications and those with both post-school and school qualifications reinforces this observation.

\section{Figure 8: Persons with No Qualifications}

Proportion in the total working-age population, employed group and available but not actively seeking work group

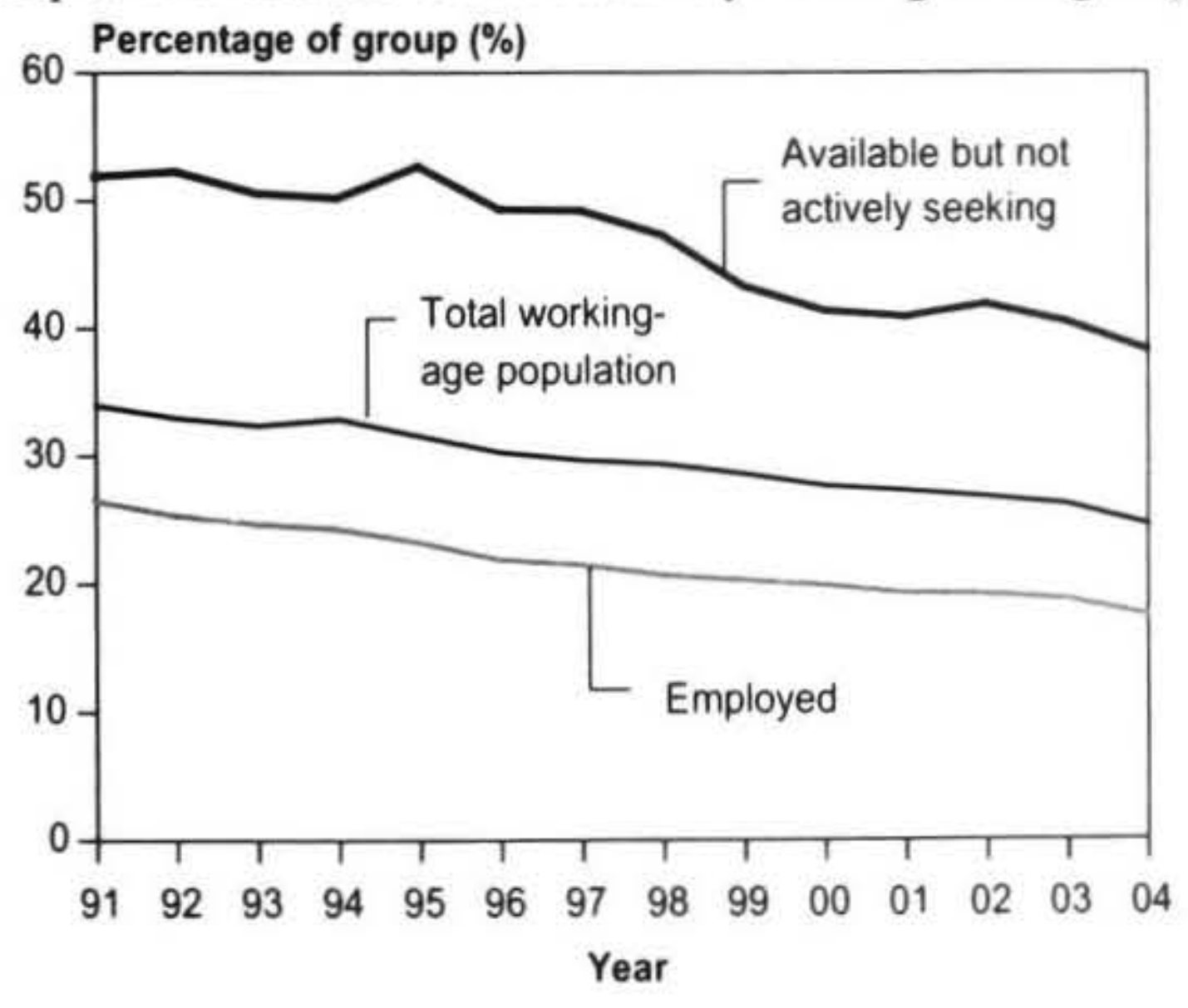

\section{Discussion}

This paper describes characteristics of the component of the working-age population that is marginally attached to the labour force. It provides an insight into the potential labour supply which is not reflected in employment or unemployment statistics.
The analysis shows that a high proportion of marginally attached persons were attending educational institutions, so they were either not available to work or not seeking work. In the long run, the economy will benefit from having a qualified and skilled workforce, but in the short to medium term, when there is a prevailing labour shortage, businesses may need to be more creative to attract this group into the labour force. Options might include creating incentives for combining work and parttime study, and optimising the use of labour when it is most readily available, for example during university breaks.

The next biggest group of marginally attached people were those with personal and family responsibilities. Incentives such as more flexible working conditions would normally be required to move people from this group into the labour force. This might include flexibility of hours, working from home and access to childcare/holiday programmes.

Not having qualifications or having a lower level of educational attainment was another barrier to the marginally attached group participating in employment. On-the-job training or other tailored training programmes may make it easier for these people to transition to the labour force.

In summary, when the unemployment rate is at low levels, there is evidence to suggest that people who were formerly marginally attached will move into the labour force. However, to fully capitalise on this group as a source of reserve labour, policies that assist the decision making of the marginally attached are required, coupled with workplace incentives, support and training once the decision to join the labour force is made.

Labour market dynamics analysis (Gray, Heath and Hunter, 2002) from Australia shows few differences between the dynamic behaviour of the marginally attached and the unemployed. The two groups have a similar probability of remaining in the same labour force state, but they are slightly different in the extent to which they move completely out of the labour force. The key difference found was that the marginally attached have more difficulty in securing a job in the short run, and many have to spend longer periods actively job searching before they find work. Further studies of labour market dynamics - for example looking at the transitions over time through the labour force states - will enhance understanding of the behaviour of the working-age population and, in particular, the behaviour of the marginally attached.

\section{References}

Australian Bureau of Statistics (2003). "Persons not in the labour force".

Broersma L, van Dijk L and van Wissen L (2004). "Making the Unused Labour Force Work: Assessing the Facts for The Netherlands", Statistics Netherlands discussion paper. 
Bryant J, Jacobsen V, Bell M and Garrett D (2004). "Labour force participation and GDP in New Zealand", New Zealand Treasury working paper 04/07.

Gray M, Heath A and Hunter B (2002). "An exploration of marginal attachment to the
Australian labour market", joint Australian Institute of Family Studies/Reserve Bank of Australia research discussion paper.

Statistics New Zealand (2003). Labour Market Statistics. www.statistics.gov.uk/OnlineProducts/ LMS_FR_HS.asp 